\title{
Proteolytic cleavage of NF-кB p65: a novel mechanism for subversion of innate immune signaling by pathogenic E. coli
}

\author{
Stephanie R. Shames ${ }^{1,2}$ and B. Brett Finlay ${ }^{1,2,3 *}$ \\ Michael Smith Laboratories, University of British Columbia, Vancouver, BC, Canada \\ 2 Department of Microbiology and Immunology, University of British Columbia, Vancouver, BC, Canada \\ ${ }^{3}$ Department of Biochemistry and Molecular Biology, University of British Columbia, Vancouver, BC, Canada \\ ${ }^{*}$ Correspondence: bfinlay@interchange.ubc.ca
}

Enteropathogenic and enterohemorrhagic Escherichia coli (EPEC and EHEC, respectively) are attaching and effacing (A/E) bacterial pathogens that cause severe diarrheal disease. An integral mechanism in the virulence strategy of A/E pathogens is the ability to subvert innate immune signaling by down-regulation of interleukin (IL)-8, a pro-inflammatory chemokine that functions to recruit neutrophils to sites of infection (Vallance and Finlay, 2000). Expression of IL-8 is stimulated by several pro-inflammatory stimuli, which interact with cellular receptors and initiate signaling cascades terminating in the expression of the IL- 8 gene (Hoffmann et al., 2002). Necessary for IL-8 gene expression is a nuclear factor- $\kappa \mathrm{B}$ (NF- $\mathrm{KB}$ ) dimer containing p65 (Rel-A). In resting cells, NF- $\kappa B$ is held inactive in the cytosol by an inhibitor of $\kappa \mathrm{B}(\mathrm{I} \kappa \mathrm{B})$; however, NF- $\kappa \mathrm{B}$-activating stimuli facilitate phosphorylation of I $\mathrm{KB}$ by an I $\kappa \mathrm{B}$ kinase (IKK) and subsequent degradation of I $\kappa$ B (Hoffmann et al., 2002). Liberated NF- $\kappa B$ dimers translocate to the nucleus where they interact with $\mathrm{\kappa B}$-containing enhancers and facilitate gene expression (Hoffmann et al., 2002).

Enteropathogenic Escherichia coli and EHEC rely on a type-III secretion system (T3SS) to dampen inflammatory signaling (Vallance and Finlay, 2000). Recently, several studies have demonstrated a role for the non-LEE encoded (Nle) effectors NleB, $\mathrm{NleC}, \mathrm{NleE}, \mathrm{NleH} 1$, and NleH2 in dampening NF- $\kappa \mathrm{B}$-mediated gene expression (Gao et al., 2009; Nadler et al., 2010; Newton et al., 2010; Royan et al., 2010; Yen et al., 2010; Baruch et al., 2011). NleB and NleE stabilize I $\kappa \mathrm{B} \alpha$ and thus limit $\mathrm{p} 65$ translocation to the nucleus, a mechanism which is shared by the T3SS effector OspZ from Shigella flexneri (Nadler et al., 2010; Newton et al., 2010). $\mathrm{NleH} 1$ and NleH2 both dampen NF- $\mathrm{B}$ mediated gene expression, but only NleH1 was shown to mediate this by decreasing nuclear abundance of ribosomal protein S3 (Gao et al., 2009; Royan et al., 2010). Four independent studies have recently shown that NleC is a metalloprotease that enzymatically degrades p65 (Yen et al., 2010; Baruch et al., 2011; Muehlen et al., 2011; Pearson et al., 2011). All four studies demonstrate that an nle $C$ null $(\Delta n l e C)$ strain of EPEC could not fully suppress NF- $\kappa \mathrm{B}$ activity or IL-8 secretion to levels of wild-type (WT) EPEC. Ectopic expression of NleC could also suppress NF- $\kappa \mathrm{B}$ activity and IL-8 secretion (Yen et al., 2010; Baruch et al., 2011; Muehlen et al., 2011; Pearson et al., 2011). All four studies identified a metalloprotease domain within NleC as essential for its function within host cells.

$\mathrm{NleC}$ is a zinc-dependent protease with a canonical HEXXH motif (Yen et al., 2010; Baruch et al., 2011; Muehlen et al., 2011). Although NleC is the first type-III secreted Zn-metalloprotease to be identified, other virulence factors have also been shown to degrade p65 to dampen the inflammatory response in the host. Chlamydia trachomatis and C. pneumoniae both utilize a T3SS to secrete chlamydial protease-like activity factor (CPAF) from chlamydial inclusions into the host cell cytosol (Christian et al., 2010). CPAF functions to degrade $\mathrm{p} 65$ and can dampen pro-inflammatory signaling in Chlamydia infected cells (Christian et al., 2010). Since Chlamydia species are obligate intracellular pathogens, it is not surprising that they encode virulence factors to dampen immune signaling. CPAF does not exclusively target p65 suggesting that NleC may also have other targets in the host cell.

The nleC gene is highly conserved between EPEC, EHEC, and C. rodentium, a natural A/E pathogen of mice, suggesting that it has a similar function in all three pathogens. The ability of NleC to dampen the release of IL- 8 in culture would suggest that a $C$. rodentium $\Delta$ nleC strain would cause increased inflammation and colitis in murine hosts. This is an attractive theory; however, NleC has little impact on C. rodentium colonization and colon weight in vivo (Kelly et al., 2006). Use of a C. rodentium nleC/nleE double knockout would likely provide additional insight into the impact of NF- $\kappa \mathrm{B}$ inhibition in vivo. NleC is the first p65-targeting metalloprotease to be identified in the effector arsenal of an extracellular pathogen. Recent insights into the function of NleC may aid in elucidating functions for other effector proteins in other pathogens. Understanding the role of effector proteins will further our understanding of their role in virulence and the pathogenic strategy of disease-causing bacteria.

\section{ACKNOWLEDGMENTS}

We would like to thank Drs. S. D. Auweter and K. M. Keeney for helpful discussions and critical reading of the manuscript. Stephanie R. Shames is an NSERC PostGraduate Trainee. B. Brett Finlay holds operating grants from the Canadian Institute of Health Research (CIHR), the Howard Hughes Medical Institute (HHMI), and the Canadian Crohn's and Colitis Foundation (CCFC). B. Brett Finlay is an HHMI International Research Scholar, and the University of British Columbia Peter Wall Distinguished Professor.

\section{REFERENCES}

Baruch, K., Gur-Arie, L., Nadler, C., Koby, S., Yerushalmi, G., Ben-Neriah, Y., Yogev, O., Shaulian, E., Guttman, C., Zarivach, R., and Rosenshine, I. (2011). Metalloprotease type III effectors that specifically cleave JNK and NF-kappaB. EMBO J. 30, 221-231.

Christian, J., Vier, J., Paschen, S. A., and Hacker, G. (2010). Cleavage of the NF-\{kappa\}B family protein p65/ RelA by the chlamydial protease-like activity factor (CPAF) impairs proinflammatory signaling in cells infected with Chlamydiae. J. Biol. Chem. 285, 41320-41327.

Gao, X., Wan, F., Mateo, K., Callegari, E., Wang, D., Deng, W., Puente, J., Li, F., Chaussee, M. S., Finlay, B. B. Lenardo, M. J., and Hardwidge, P. R. (2009). Bacterial effector binding to ribosomal protein s3 subverts 
NF-kappaB function. PLoS Pathog. 5, e1000708. doi: 10.1371/journal.ppat.1000708

Hoffmann, E., Dittrich-Breiholz, O., Holtmann, H., and Kracht, M. (2002). Multiple control of interleukin-8 gene expression. J. Leukoc. Biol. 72, 847-855.

Kelly, M., Hart, E., Mundy, R., Marches, O., Wiles, S., Badea, L., Luck, S., Tauschek, M., Frankel, G., RobinsBrowne, R. M., and Hartland, E.L. (2006). Essential role of the type III secretion system effector NleB in colonization of mice by Citrobacter rodentium. Infect. Immun. 74, 2328-2337.

Muehlen, S., Ruchaud-Sparagano, M. H., and Kenny, B. (2011). Proteasome-independent degradation of canonical NF\{kappa\}B complex components by the NleC protein of pathogenic E. coli. J. Biol. Chem. 286, 5100-5107.

Nadler, C., Baruch, K., Kobi, S., Mills, E., Haviv, G., Farago, M., Alkalay, I., Bartfeld, S., Meyer, T. F., BenNeriah, Y., and Rosenshine, I. (2010). The type III secretion effector NleE inhibits NF-kappaB activation. PLoS Pathog. 6, e1000743. doi: 10.1371/journal. ppat. 1000743
Newton, H. J., Pearson, J. S., Badea, L., Kelly, M., Lucas, M., Holloway, G., Wagstaff, K. M., Dunstone, M. A., Sloan, J., Whisstock, J. C., Kaper, J. B., Robins-Browne, R. M., Jans, D. A., Frankel, G., Philips, A. D., Coulson, B. S., and Hartland, E. L. (2010). The type III effectors NleE and NleB from enteropathogenic E. col and OspZ from Shigella block nuclear translocation of NF-kappaB p65. PLoS Pathog. 6, e1000898. doi: 10.1371/journal.ppat.1000898

Pearson, J. S., Riedmaier, P., Marches, O., Frankel, G., and Hartland, E. L. (2011). A type III effector protease NleC from enteropathogenic Escherichia coli targets NF-kappaB for degradation. Mol. Microbiol. doi: 10.1111/j.1365-2958.2011.07568.x. [Epub ahead of print].

Royan, S. V., Jones, R. M., Koutsouris, A., Roxas, J. L., Falzari, K., Weflen, A. W., Kim, A., Bellmeyer, A., Turner, J. R., Neish, A. S., Rhee, K. J., Viswanathan, V. K., and Hecht, G. A. (2010). Enteropathogenic E. coli non-LEE encoded effectors NleH1 and NleH2 attenuate NF-kappaB activation. Mol. Microbiol. 78, 1232-1245.
Vallance, B. A., and Finlay, B. B. (2000). Exploitation of host cells by enteropathogenic Escherichia coli. Proc. Natl. Acad. Sci. U.S.A. 97, 8799-8806.

Yen, H., Ooka, T., Iguchi, A., Hayashi, T., Sugimoto, N., and Tobe, T. (2010). NleC, a type III secretion protease, compromises NF-kappaB activation by targeting p65/ RelA. PLoS Pathog. 6, e1001231. doi: 10.1371/journal. ppat.1001231

Received: 15 February 2011; accepted: 19 February 2011; published online: 01 March 2011.

Citation: Shames SR and Finlay BB (2011) Proteolytic

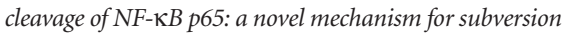
of innate immune signaling by pathogenic E. coli. Front. Microbio. 2:38. doi: 10.3389/fmicb.2011.00038

This article was submitted to Frontiers in Cellular and Infection Microbiology, a specialty of Frontiers in Microbiology. Copyright $(2011$ Shames and Finlay. This is an open-access article subject to an exclusive license agreement between the authors and Frontiers Media SA, which permits unrestricted use, distribution, and reproduction in any medium, provided the original authors and source are credited. 